\title{
"The Second Vice is Lying, the First is Running into Debt." Antecedents and Mitigating Practices of Social Debt: An Exploratory Study in Distributed Software Development Teams
}

\author{
Tim Dreesen \\ University of Cologne \\ dreesen@wiso.uni- \\ $\underline{\text { koeln.de }}$
}

\author{
Phil Hennel \\ University of Cologne \\ hennel@wiso.uni- \\ koeln.de
}

\author{
Christoph Rosenkranz \\ University of Cologne \\ rosenkranz@wiso.uni- \\ koeln.de
}

\author{
Thomas Kude \\ ESSEC Business \\ School, Paris \\ kude@essec.com
}

\begin{abstract}
Although much is known about the concept of technical debt in software development, less is known about its social counterpart, also known as social debt. Social debt refers to future consequences of decisions related to people and their interactions. Omissions in social interactions or reduction of communication can foster social debt - and in turn result in negative outcomes in the long run. In this paper, we explore what factors drive and mitigate social debt in distributed agile software development teams. Utilizing an exploratory case study approach, we derive insights from two case organizations. We present antecedents and mitigating factors of social debt related to communication, collaboration, and coordination.
\end{abstract}

\section{Introduction}

The advent of digital transformation all across the globe [29, 33, 54] has led to a similar rise in agile software development (ASD) teams [12, 34, 42], becoming the de facto standard and dominant mode of operation for software development. Nowadays, more than $90 \%$ of software development teams report to use agile management or engineering practices such as daily standups, continuous delivery, or pair programming in their daily work [63].

Traditionally, agile software development has been associated with close, personal interaction in small, self-organizing, and co-located teams [31, 34], and working face-to-face in close interaction is deemed desirable for many agile practices to unleash their potential $[34,51]$. At the same time, however, industry has put forward techniques such as the Scaled Agile Framework [13, 19, 41], which promote that agile software development can be scaled up to far larger and even distributed teams.

As a result, more and more organizations engaged in ASD continue to support and encourage team collaboration across geographic boundaries and time zones [21, 63]. The COVID-19 pandemic outbreak and the resulting global health crisis of 2020 indeed may prove to be a turning point that will ultimately lead to an additional increase in distributed teams as a "new normal" because many employees are now forced to work from home due to safety and health rules [e.g., 14, 16, 48, 56].

Existing studies on distributed ASD teams highlight that further demands are placed "on the development process through the increased complexity related to communication, coordination, cooperation, control, and culture, as well as to technology and tools" [2]. These findings indicate that less co-location could lead to less interaction of team members [15, 20, 27], and the long-term effects of prolonged distancing are not known. Prior work suggests that less interaction may contribute to the build-up of what recently has become referred to as "social debt" [59], in terms of the future consequences of decisions related to people and their interactions. Social debt can be an important challenge for software development teams because similar to technical debt [17], a lack of interaction in the present may entail substantial challenges in the future. However, what exactly causes social debt to increase, and what mechanisms help to mitigate or decrease its adverse effects, is currently not known.

In the current situation caused by the COVID-19 pandemic, distribution and distance working are no longer voluntary but mandatory and enforced for almost all team members. With the added distraction of caring for elderly, sick, or children, we would expect even less social interaction and exchange. In other words, the challenges related to social debt can be expected to loom particularly large in the current situation. In addition, understanding the causes of accumulating social debt is important as its negative consequences may materialize later when teams begin to work on-site again.

We study social debt in ASD teams in this current context of non-voluntary work-from-home caused by the COVID-19 pandemic. We aim at answering the 
following research question: What are the drivers of social debt in distributed ASD teams, and what are factors mitigating the build-up of social debt?

To answer this question, we conducted an exploratory case study of eight ASD teams in two organizations. Our results show that various factors contribute to or help mitigate social debt in ASD teams and that these factors can be distinguished as communication, collaboration, and coordination factors (the 3C Model; [26]).

Based on these findings, we contribute to the conceptualization of social debt in software development by shedding light on the drivers and antecedents of social debt. We theorize that specific mitigating patterns help to decrease these effects. This contributes to our understanding of distributed ASD teams, and the role of social debt in these.

In the following, we give an overview of prior work. This is followed by a description of the cases and the research method. Subsequently, we present the results of our analysis. Finally, we discuss our results, implications, and limitations.

\section{Theoretical Background}

\subsection{Distributed \& Agile Software Development}

Approaches for developing software range from sequential and plan-driven [52] to agile and iterative approaches [7]. ASD methods [e.g., 8] rely on sets of management practices, development practices, and standards and norms [51], which collectively lead to a trade-off between strict control and flexibility and autonomy within the team. Moreover, the overall development process is not planned and scheduled upfront, and progress is made in small iterative phases, while encouraging change and constant feedback [11]. Planning becomes a permanent task, and team leadership is established via collaboration and is separated from project lead [23]. All of this builds heavily on co-location [5], communication [34], and social interaction [35] of team members.

Thus, the team and its interaction are highlighted as the crucial aspect of ASD in industrial practice. However, extant research has investigated mainly individual or organizational phenomena, such as the use and effects of specific agile practices [e.g., 3, 43], or effects regarding whole projects or organizations, such as scaling agile methods to large-scale projects $[13,37]$.

As opposed to individual and organization-wide effects of agile methods, team-level effects are covered less, and existing results are contradictory. Team research has included technology as an influencing factor of team work [e.g., 39], but specific features of agile methods have not been observed. Research found that cohesive teams are the optimal base for applying agile practices [8, 28], while other studies suggest that diversity amplifies creativity and problem-solving ability [4, 40] and therefore might provide benefits for ASD. These inconsistencies are especially important for ASD, as ASD teams rely heavily on efficiency [to respond quickly to changes; 12] and problem-solving ability [to complete complex, non-routine tasks; 40].

Only limited research goes deeper into social aspects of agile teams in general and distributed teams in particular $[18,30]$. For instance, Sarker and Sarker [55] provide insights into the optimal harnessing of agile methods in geographically distributed projects. Similarly, Iivari and Iivari [36] explain the relationship between organizational culture and ASD, especially in emergent stages.

We argue that there is a need to close this gap, as agile methods - for co-located, but even more so for distributed teams - rely heavily on communication and social interaction between team members. One of these social aspects has the potential to explain lagged negative effects: social debt.

\subsection{Social Debt in Software Development}

Social debt can be best described by its parallel characteristics to technical debt [58]. The concept of technical debt in the field of software development has a history of almost 30 years [6]. First introduced in 1992 by Cunningham [17], technical debt refers to the negative consequences that arise from omissions, compromises, or simply bad software development, often years later $[6,17]$.

Building on this, the concept of social debt as the "social" counterpart to technical debt recently has been introduced to the software development community [58]. Social debt as defined by sociology "represents the set of strained social relationships that emerges as a consequence of debtor-creditor circumstances" [45]. Building on this and combining it with technical debt's idea of omissions, compromises, or bad behavior [58], social debt has been conceptualized for the first time by Tamburri, Kruchten, Lago and Van Vliet [59] as "a cumulative and increasing cost in the current state of things, connected to invisible and negative effects within a development community." These effects are closely linked to undesirable, often implicit characteristics in the organizational and social structure of development communities, and produce additional costs, (e.g., increase in time or budget) [59]. For instance, missing out on regular meetings due to scheduling issues (i.e., "compromises") or having 
irregular and chaotic communication patterns (i.e., "omissions") might lead to missing knowledge in later stages across the team, potentially leading to misinformed decisions or conflict - possibly on a task level or relationship level - in the future. Similar to technical debt, the effects of current actions might only show later on, but might therefore be more difficult to deal with [59].

Building on this, Tamburri and colleagues made initial steps in transferring the concept from sociological literature to software development research [58], and deriving an interpretative framework of social debt from industry observations [59]. Further, social debt has been applied as a concept within the context of community health in open source in general [61] and incommunicability [60]. According to Tamburri and colleagues, "Social debt is analogous to technical debt in many ways: it represents the state of software development organisations as the result of 'accumulated' decisions. In the case of social debt, decisions are about people and their interactions" [59].

Social debt supposedly plays an important role for three core aspects of teamwork: communication, collaboration, and coordination; also known as the 3C model [26]. As described, social debt can occur by omissions, compromises, or bad behavior - all three of which can occur in communication (e.g., slacking on regular communication), collaboration (e.g., not seeking or giving help to colleagues), and coordination (e.g., not having a clearly distributed set of responsibilities).

While this concept thus clearly has the potential to uncover more antecedents of the social aspects related to why projects fail or succeed, specifically in distributed situations, only few studies exist. We conducted a structured literature review on social debt in software development across leading journals (i.e., the AIS Senior Scholar's Basket of Eight, Academy of Management Journal and Review, Empirical Software Engineering, IEEE Organization Science, IEEE Software, Journal of Software and Systems, Communications of the ACM) and conferences (i.e., CHI, CSCW, ECIS, ICIS, ICSE, IEEE/ACM International Conference on Automated Software Engineering, HICSS, PACIS) in software development, management, and information systems, which led to a total of nine results, of which only four were investigating or including this concept - all of which were (co-)authored by Tamburri [58-61].

\subsection{Social Capital, Psychological Safety, and Control}

The concept of social debt shares some similarities, but also important differences, with the notion of social capital. The construct of social capital describes resources - tangible and intangible which are within and derived from social relationships among actors [1, 46]. Utilized for exploring social interactions, mostly in conjunction with aspects of power, influence, or control, social capital can be divided into three clusters of attributes: the structural cluster, referring to how openly and freely actors share information; the relational cluster, which refers the relationships that formed over time; and the cognitive cluster, referring to a collective and shared meaning and understanding [46]. Although different and distinct concepts, the notions of social capital and social debt share some similarities and are related to each other, especially as regards to relational attributes. Building social capital can be seen as a process of building attributes such as trust, relationships, and a shared understanding - all signs of a well-working team with a high level of psychological safety $[30,50]$, and presumably a low level of social debt.

It is important to note that social capital is not a "currency" to pay back social debt, or to convert one into the other. "Spending" social capital, in terms of relying on social capital, might influence the build-up of social debt, but as Tamburri and colleagues found, social debt cannot be "paid back" easily. In that regard, it shows more similarities with its technical counterpart - technical debt [59]. In fact, depending on how social capital is made use of, it may not only decrease (e.g., when bringing the team together) but also increase social debt. If single actors use their social capital for their own goals instead of the team's goals (e.g., by misusing their relationships or trust), then this might lead to negative outcomes as described in the previous section. For instance, if developers use their social capital to force omissions in the general communication patterns or to coerce compromises, the results may lead to social debt, and might undermine the positive influences that enabled the building of social capital in the first place.

A related concept well-known in research on teams is psychological safety, which refers to the perceived climate and the perception's effect on the actors' resulting behavior [24, 30]. The concepts of social capital and psychological safety are interconnected by their inclusion of cohesivenesssupporting attributes (e.g., trust, open and honest communication). Still, these concepts look at different aspects: social capital is focused on the individual actors and their place within the social network, whereas psychological safety is more concerned perceptions of the team.

Activities of "spending" social capital resemble a form of clan control - the act of socialization of team 
members with sets of valued norms and emphasis of acceptable behaviors. In this context common rituals and experiences, are essential for the development of clan control. Rituals in which teams are brought together in an informal setting and which are characterized by open communication can have a positive effect on the reduction of social debt [22, 32, 38].

\section{Research Design}

\subsection{Method and Overview}

To explore how social debt is occurring in and what effects this has on distributed ASD teams, we conducted an embedded, exploratory multiple-case study [64] in two different case organizations. The cases were sampled following a theoretical sampling strategy and all surveyed organizational units are based in Germany. Both case organizations are large insurance companies: Multiguarant is active internationally and Coverall only nationally, and both are in the process of undergoing larger digital transformation initiatives, which started in both approximately two years ago. ${ }^{1}$

In general, both case organizations were faced with major challenges with the outbreak of the COVID-19 pandemic. Immediately after the social distancing orders and closure of nearly all retail and service industry came into effect in Germany around March $17^{\text {th }}, 2020$, both case organizations saw themselves closing their offices and compelling most of their employees to continue working from home.

Both companies had to quickly ensure that team members would be able to communicate and collaborate from home using the infrastructure and tools at their disposal. In addition, team leaders and managers were obliged to develop alternatives to their existing coordination and control mechanisms [38], as many of the processes that had been in place until then were mainly based on the physical presence of employees in the local offices (e.g., physically close behavior control of employees through observations).

\subsection{Data Collection and Analysis}

We collected data from various data sources and with different data collection methods. Semistructured interviews and project documentation were used to generate data. We interviewed members of eight agile software development teams, three from Multiguarant and five from Coverall (see Table 1). Administrative documents, work descriptions,

\footnotetext{
${ }^{1}$ Company names are anonymized due to confidentiality.
}

interview transcripts, and field notes were collected in a case study database. Each team was interviewed twice, once at the beginning of the wide-spread adoption of home office directives, and once after an average interval of three weeks. The initial interviews have an average duration of 60 minutes whereas the follow-up interviews have an average duration of 15 minutes. Overall, we collected data from March to June 2020 while conducting 16 remote interviews with a total of 18 interviewees. All interviews were audio-recorded and transcribed, resulting in roughly 206 pages.

Afterwards, we applied different coding strategies following guidelines for inductive coding [44, 53] and exploratory, theory-generating case studies [25]. Our two-step data analysis process started with open coding based on the interview transcripts. This started while data collection was still ongoing. We aimed to identify important aspects and concepts, which could be analyzed in more detail in the next coding step $[9,57]$. The theoretical lenses of social capital $[1,46]$ and social debt [45] provided initial seed codes.

In the second step, we set out to identify and refine our codes by means of pattern coding [44, 53], which is appropriate for the development of major themes from data. These codes are capable to "identify an emergent theme" and therefore are helpful for "grouping those summaries into a smaller number of sets, themes, or constructs" [44]. We integrated the resulting findings and analyzed the different interdependencies and their impacts on our newly identified themes and patterns. The 3C model [26] was used as a lens for categorizing these patterns on a high level.

Table 1: Cases and Informants

\begin{tabular}{|l|l|l|}
\hline & Multiguarant $^{\mathbf{1}}$ & Coverall $^{\mathbf{1}}$ \\
\hline Industry & Insurance & Insurance \\
\hline Size & $\begin{array}{l}\text { Large, international } \\
\text { company }\end{array}$ & Large, national company \\
\hline Teams / & $\begin{array}{l}3 \text { teams, 6 interviews: } \\
\text { Inter- } \\
\text { viewees } \\
\text { product owner, a scrum } \\
\text { master and developers }\end{array}$ & $\begin{array}{l}\text { 5 teams, 10 interviews: } \\
\text { three team leaders, two } \\
\text { test managers and } \\
\text { developers }\end{array}$ \\
\hline
\end{tabular}

\section{Findings}

In order to establish the necessary foundation in making work-from-home applicable (e.g., infrastructure, software tools, hardware, organizational measures, etc.) both case companies had to master different efforts. While in the case of Multiguarant, which are engaging in distributed development, the corporate culture within the IT service unit is already characterized by home office regulations, a different picture emerges with 
Coverall. Depending on the project situation, it has long been common practice at Multiguarant that developers carry out parts of their work from their home office, whereas home office regulations are the exception rather than the rule in Coverall.

"Home office was a possibility before the crisis, but was rather sparse (max. one day and only after consultation with the supervisor) and still in its early stages. "(Lionel, Test Manager

As a result, Multiguarant required comparatively few adjustments for the full work of all developers from home. This mainly concerned the scaling of hardware and software (in terms of extending existing licenses).

"Well, I live 500 meters from my office. But I've been doing home office for four or five years now, of course with just one day, and that's now totally expanded, and I've been sitting at home for five weeks now and it's no change for me at all." (Jane, Developer)

Coverall, on the other hand, had set itself the task of building the corresponding infrastructure from scratch within two weeks. The most important task was to provide video-conferencing tools to ensure communication and to set up a virtual private network (VPN) to access company resources from home. Coverall was able to achieve both goals on schedule with great effort.

\begin{abstract}
"So, we were in a relatively bad position with regard to the home office situation. We couldn't just work over normal internet connections. We need a secure SVN transfer, especially in our industry. On top of that, there was a notebook bottleneck, which unfortunately has been with us for months. And after one week it worked, one week later I even had my own notebook, since then I work productively from home." (Marlon, Developer)
\end{abstract}

Nevertheless, evidence has been found which suggests that work under these conditions differs fundamentally to such an extent that it encourages the accumulation of social debt. Our study revealed a set of 18 conditions that significantly influence the phenomenon of social debt. Table 2 summarizes all of the identified antecedents and drivers of social debt.

Overall, factors that we linked to social debt were mentioned and reported in both case organizations and all projects. Specifically, we observed two sets of categories in relation to social debt: antecedents and drivers of social debt as well as mitigating practices. Both were categorized and combined according to the 3C model [26, 47].

First, antecedents and drivers of social debt are conditions that favor the accumulation of social debt. These include, for instance, 'lack of communication depth', 'lack of consistency in employee availability' and 'lack of leadership'

Overall, the majority of the identified antecedents and drivers could be associated to the 'communication' aspect of the 3C model. For example, the fundamental lack of depth of communication is caused by the missing conveyance of information through emotions and facial expressions. In one instance this is reflected in the fact that one-on-one conversations of supervisors (with their employees) are initially postponed:

"There are such problems [ref. to social debt]. Because nothing is worse than having a personal conversation remotely. Because there are many factors that are incredibly important in such a conversation. Because I have to tell you that I also have to show a co-worker, whom I actively criticize, a little bit by other factors, by posture, gestures and so on. [...] I have to find another way, and then I don't know what another solution is. But I guess you just have to push some things back and if I can't have a personal conversation with an employee, I'm not going to roll the subject out in a conference call." (Sam, Team Lead)

Closely related to this is the fact that distance communication tends to be misinterpreted and thus promotes a lack of common ground or shared understanding:

"These coordination meetings... yeah, I don't know if home office is a hindrance. I'm just a fan of personal conversations and I think emotions are particularly helpful in personal conversations because we work a lot with telephony, not video conferencing. If you read faces better, you can't necessarily misinterpret messages." (Lionel, Test Manager)

In fact, we have been able to identify cases where these circumstances have contributed to alleged social conflicts, which have been further aggravated by a lack of informal and unintended communication (e.g., face-to-face conversations through visits in a colleague's office room, kitchen, cantina etc.):

"My colleague had replied quite strangely at once, in emails. I haven't seen him for months. At least I haven't been able to make a video-call with him. And he always answered mails, not only from me, but also from other colleagues very snappish and shor. And then a colleague and I really thought about what was wrong with him? Then he wasn't available, so you just couldn't get hold of him, which caused a bit of trouble. If we were all in the office now, I would have simply gone into his office and said: 'What is going on? What's the problem? Shouldn't we talk about it, shouldn't we go out for coffee somewhere?' It was just too bad because I couldn't get it straightened out. It would have been different in the office, definitely different." (Claire, Developer) 
Table 2: Antecedents of Social Debt

\begin{tabular}{|c|c|c|}
\hline \multicolumn{2}{|c|}{ Driver } & \multirow{2}{*}{$\begin{array}{l}\text { Short description } \\
\text { Remote communication is less meaningful. For example, emotions, reflected through } \\
\text { gestures and other physical features are missing or reduced. }\end{array}$} \\
\hline \multirow{6}{*}{ 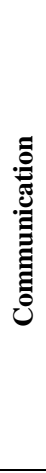 } & Lack of Communication Depth & \\
\hline & Lack of Communication Latency & $\begin{array}{l}\text { Remote communication is characterized by higher complexity and is therefore slower or } \\
\text { staggered compared to collocated face-to-face communication. }\end{array}$ \\
\hline & Lack of Feedback Loops & $\begin{array}{l}\text { Feedback loops in terms of business-related information have become less or are missing } \\
\text { completely. }\end{array}$ \\
\hline & Lack of Informal Communication & $\begin{array}{l}\text { Informal communication methods (e.g., via non-structured, ad-hoc talks) have been } \\
\text { replaced via more structured communication methods (e.g., email or documentation). }\end{array}$ \\
\hline & Lack of Shared Understanding & $\begin{array}{l}\text { Remote communication tends to be misinterpreted (e.g., through a lack of depth) and } \\
\text { overall communication volume and frequency can be reduced. }\end{array}$ \\
\hline & $\begin{array}{l}\text { Lack of Unintentional } \\
\text { Communication }\end{array}$ & $\begin{array}{l}\text { Communication is planned and scheduled upfront and is less spontaneous (e.g., no more } \\
\text { visits in a colleague's office room, kitchen, cantina etc.). }\end{array}$ \\
\hline \multirow{4}{*}{ 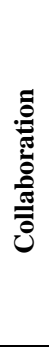 } & $\begin{array}{l}\text { (Unintentional) Lack of Conflict } \\
\text { Resolution }\end{array}$ & $\begin{array}{l}\text { Conflicts are addressed and resolved less frequently, and working from home enforces } \\
\text { general (superficial) agreement instead of solving conflicts. }\end{array}$ \\
\hline & $\begin{array}{l}\text { Intensity of Task-Related } \\
\text { Collaboration* }\end{array}$ & Interactions through remote work are highly task-related and goal-orientated. \\
\hline & $\begin{array}{l}\text { Lack of consistency in employee } \\
\text { availability }\end{array}$ & $\begin{array}{l}\text { Availabilities of team members are unregularly, not transparent (or at least not } \\
\text { transparently communicated) or synchronized. }\end{array}$ \\
\hline & $\begin{array}{l}\text { Lack of Knowledge Transfer } \\
\text { Capabilities }\end{array}$ & $\begin{array}{l}\text { (Planned) knowledge transfer is reduced or postponed. For example, trainings are } \\
\text { cancelled, postponed, or do not meet the quality standards compared to previous on-site } \\
\text { trainings. }\end{array}$ \\
\hline \multirow{5}{*}{ 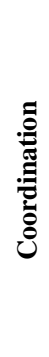 } & Lack of Coordinative Mechanisms & $\begin{array}{l}\text { Rules, schedules, and other activities (e.g., core working hours) necessary for remote } \\
\text { teamwork have not been set up or are loosened. }\end{array}$ \\
\hline & Lack of Formal Control (Behavior) & $\begin{array}{l}\text { Behavior of team members cannot be observed, thus deviations from the desired behavior } \\
\text { cannot be identified. }\end{array}$ \\
\hline & $\begin{array}{l}\text { Lack of Informal Control (Clan } \\
\text { Control) }\end{array}$ & $\begin{array}{l}\text { The use of values and norms that promote teamwork and at the same time are in line with } \\
\text { the company's goals, are not yet fully established or are missing altogether. }\end{array}$ \\
\hline & Lack of Leadership & $\begin{array}{l}\text { Common leadership tasks (e.g., inspiring, encouraging, or supporting the team) are } \\
\text { neglected. }\end{array}$ \\
\hline & Lack of Transparency & Visibility in contexts related to the behavior of individuals or groups is missing. \\
\hline & \multicolumn{2}{|c|}{ LEGEND: *'Intensity of Task-Related Collaboration' has been the only factor, that has both a promoting and mitigating effect } \\
\hline
\end{tabular}

The above statement also illustrates that from a collaboration perspective, fewer conflicts are generally addressed and resolved (lack of conflict resolution). Apart from the communication aspect, a basic attitude also seems to contribute to making concessions and avoiding conflicts:

\begin{abstract}
"It's just that there's a conflict shyness or conflict avoiding behaviour. That you only ever want to agree to something first. Because this not agreeing and going into conflict is more exhausting. And it's definitely intensified by the home office." (Marlon, Developer)
\end{abstract}

But problems also arise in processes of the team members' everyday collaboration. For example, availabilities of colleagues are irregular, invisible for others, and not synchronized. Common working hours of team members lack consistency, or are even missing:

"If we have to fall back on other teams I have found that the accessibility is actually much worse. They simply sat down around 10 or 11 p.m. until the evening hours there
[...]. Before COVID-19, you just walked one door further and you could talk to your colleagues or ask them in the corridor. So that's gone. I have to admit that this is a handicap in the work flow, because no direct agreement was possible. Because they couldn't be reached by phone. And also on Skype they were either busy or [...] with their teams in other meetings and so on." (Martha, Test Manager)

In a similar way, problems arose through the isolation itself. For instance, being able to focus solely on programming, not needing to make hold contact to anyone else, made developers more prone to working overtime, missing breaks, or being unreachable:

"So I am really always programming. Therefore I have to be very disciplined [to keep my breaks and working hours]." (John, Developer)

"What I noticed is [...] when the notebook is within reach at home and you're actually already off work, then you get itchy fingers from time to time to check your e-mails once more. I repeatedly found myself sitting at my 
Table 3: Mitigators of Social Debt

\begin{tabular}{|l|l|l|}
\hline \multicolumn{2}{|l|}{ Mitigator } & Short description \\
\hline \multirow{2}{*}{$\begin{array}{l}\text { Honest and Open Communication } \\
\text { Communication }\end{array}$} & $\begin{array}{l}\text { Communication is characterized by honesty and openness, the members trust each other. } \\
\text { the information exchange are not random and have been determined or prepared in advance. }\end{array}$ \\
\cline { 2 - 3 } & $\begin{array}{l}\text { Intensity of Task-Related } \\
\text { Commity of Task-Related }\end{array}$ & $\begin{array}{l}\text { Interactions through remote work are highly task-related and goal-orientated. All collabo- } \\
\text { rative actions are oriented towards completing the task at hand, distractions are reduced. }\end{array}$ \\
\cline { 2 - 3 } & $\begin{array}{l}\text { Reduced Upfront Costs for } \\
\text { Initializing Interactions or } \\
\text { Communications }\end{array}$ & $\begin{array}{l}\text { quickly and without almost any restrictions (e.g., free meeting rooms are no longer a scarce } \\
\text { resource). }\end{array}$ \\
\hline & *Intensity of Task-Related Collaboration has been found the only factor, that has both a promoting and mitigating effect \\
\hline
\end{tabular}

notebook for another 15 minutes, even though I had already off work. I just don't punch out at home like I would at the office." (Axel, Business Analyst)

This has also implications for the overall coordination of team members. Studies show that especially in distributed software development environments the practice of synchronizing working hours is of vital importance [21, 34, 49].

Closely related to this is the issue of control. On the one hand, because traditional control modes such as outcome or behavior control are difficult to implement in distributed ASD environments [e.g. 38]. If, for example, behavior is no longer controlled and employees follow their work routines in a Wild West "cowboy" manner, problems arise in collaboration (e.g., availability of team members) which, in turn, lead to discontent or even serious social conflicts. However, this also concerns informal controls, especially the exercise of clan control, that is, socializing of team members into sets of valued norms in order to reinforce acceptable behaviors through shared rituals and experiences [e.g. 10, 22, 38]. The lack or total absence of common values and norms consistent with organizational goals leads to more social debt being built. Concrete manifestations result, for example, out of the behavior of postponing scheduled meetings or even avoiding colleagues "remotely":

"Well, many meetings were cancelled or postponed indefinitely on the grounds that, yes, it just doesn't work at the moment without the feeling that there is a serious will behind it to actually let it happen. If you just say, 'Uh, it's not really convenient for me,' I'll take that as a reason to postpone it. Finally, it can be observed that team leaders and other supervisors neglect their leadership activities."

"It's easier to avoid each other. So, if I don't want to communicate with someone in a web meeting, then I'll certainly find my ways to do so. This is certainly different when people sit together in an office" (Kurt, Team Lead)
Second, the teams employed various mitigating practices, that is, codified or routinized patterns of action which reduce or counter the built-up of social debt (see Table 3). For example, 'honest and open and communication' together with 'Reduced upfront costs for initializing interaction and communication' contribute to an environment, in which social conflicts may be addressed and solved more easily and social debt can be decreased:

"In work situations, I find that the communication is actually more direct, because there is perhaps a bit more distance. I have also had a few meetings where I thought: 'Wow, maybe your tone is a bit strict here.' Maybe because there is higher potential for frustration when you sit in front of your notebook. So I would say the meetings were very constructive." (Heath, Team Lead)

Moreover, our data revealed another aspect that plays a role in mitigating the effects of the drivers on social debt. The concept of psychological safety is related to an increasing experience with working from home over time:

"What I have noticed in the meantime is that people in our department [are] very openly talk[ing] about it. For example, they say: 'Wow, last week I had a complete down phase.' What I found cool was that it could be talked about - in a circle of 15, 20 people. Without it being an obstacle. And I have the feeling that [...] you feel so close to each other [...] sure you probably still run into conflicts somehow. [...] but I already have the feeling that these conflicts will be discussed and expressed directly" (Kurt, Team Lead)

\section{Discussion}

Building upon our research question, the main goal of this research project was to shed light upon the question of what factors influence social debt, taking into account the enforced "work from home" environment during the COVID-19 pandemic. Based on our results, we were generally able to provide answers to our research question and enhance our 
knowledge on social debt in ASD teams from both a theoretical as well as practical point of view.

First, we contribute to the theorization of social debt by conceptualizing it for the first time in a distributed software development setting. We show that the build-up of social debt indeed is an issue in these scenarios. In future studies, linking the conceptualization of social debt more closely to established theories such as social capital theory, psychological safety, or control theory would help to increase construct validity.

Second, we propose fifteen antecedents of social debt, which are comparatively more detailed and fine-grained than the abstract causal effects identified by Tamburri, Kruchten, Lago and Van Vliet [59]. Categorized according to the $3 \mathrm{C}$ model, some of these are related to communication, others to coordination or collaboration, and some to all three. As expected, all of them are related to social interactions, and especially the pitfalls of distancebased interaction. We could not identify any drivers that are not related to social interaction. Future studies could investigate these drivers using specific theories such as media naturalness theory. Managers and team members alike need to be aware of these potential drivers in order to be able to counter them. With the increased likelihood that working from home will increase in the future, this issue may get even more urgent. Wide-spread adoption of an ASD scaling framework (e.g., SAFe) was not present in our study. Scaling frameworks and ASD methods in general need to take these findings into account. In the future, they may even learn from tools and techniques used by the open source community (e.g., citizen's guides, mentorship, online tools), which has been developing software in a distributed manner for a long time.

Third, we provide a base line and call for research for developing new or modifying existing ASD scaling frameworks. Existing scaling frameworks developed from existing "unscaled" frameworks (e.g., Scrum of Scrums from Scrum), and in part already pay attention to distributed teams. However, this study provides additional factors to keep in mind and to utilize for modifications or innovations regarding ASD scaling frameworks.

Fourth, we show that mitigating practices, which are closely linked to communication and collaboration, such as increasing the frequency and intensity of distance social interaction, help to prevent the built-up of social debt by addressing the drivers. Future studies could explore the relation between these mitigating practices and other management or technical practices [51], or social practices [35] of ASD.
Looking more closely on our contributions to ASD literature compared to literature on general team research, we would argue that many of our findings can be transferred to general team research. However, our sample includes only personnel active in software development contexts and, more importantly, teams following specific ASD methods. Therefore, our contributions are first and foremost targeted towards ASD research and requires additional confirmation in different contexts for transferability to general team research.

The main limitation of our study lies in its - by design - limited research method. Especially the selection of only two case organizations from a single industry may limit a broad generalization of results in general. We therefore call for replication of our study in different contexts, with organizations of different sizes, industries, country, and overall agility. Further, we made use of qualitative methods only, enabling us to focus on a single method and going into more detail but also limiting the reliability of our findings to a certain extend. By including quantitative methods and by replicating our study with a quantitative or mixed methods approach, future research could further improve the reliability of our findings. Another limitation lies in the selection of participants. While all major roles of each team were interviewed, we did not conduct interviews with each and every team member. It is likely that perceptions of factors influencing social debt vary. We tried to mimnimize the influence of social desirability bias. However, due to the clear favor of success over failure, social desirability bias was still likely to emerge from questions during our interviews. Lastly, we do not have data on the long-term effects of social debt, or of the interplay between technical and social debt. We also do not know if social debt is more likely to occur in distributed than in co-located settings, but its close link to social interaction makes this probable.

Future studies may investigate the specific causeeffect mechansims at play in distributed teams, compare co-located and distributed teams, or investigate the effect of social debt on other outcomes such as job satisfaction [62]. With regard to the ongoing COVID-19 pandemic, we hear a lot about the "new normal" after the pandemic. Our study suggests that for some ASD teams, the new normal may involve dealing with the potentially considerable amount of both social and technical debt that has built up during the extended time of distributed work. Future research may build on our work may study the actual cost arising from social debt in the aftermath of the pandemic and how teams handle it. Whereas some teams may struggle, others 
may even leverage the unusual situation and external triggers to grow even more into a mindful and tightknit group, thus entirely avoiding social debt. It will be interesting to study in more detail what can be learned more generally from this extreme situation about distributed ASD teams.

\section{Conclusion}

In this paper, we identified what factors drive and mitigate social debt in ASD teams. Based on our qualitative approach, we were able to derive our insights from two case study organizations, therefore further extending the scientific communities' knowledge about social debt in ASD. Surprisingly, we found a higher number of factors increasing social debt than those that have a decreasing effect. We gave an overview over these factors and related them according the concepts communication, collaboration and coordination of the $3 \mathrm{C}$ model. Further, we discussed implications for both theory and practice. Limitations were discussed as well as avenues for future research were pointed out.

\section{References}

[1] Adler, P.S., Kwon, S.-W.: Social capital: Prospects for a new concept. Academy of management review 27, (2002), pp. $17-40$

[2] Ågerfalk, P.J., et al.: Flexible and Distributed Information Systems Development: State of the Art and Research Challenges. Information Systems Research 20, (2009), pp. 317-329

[3] Balijepally, V., et al.: ARE TWO HEADS BETTER THAN ONE FOR SOFTWARE DEVELOPMENT? THE PRODUCTIVITY PARADOX OF PAIR PROGRAMMING. MIS Quarterly 33, (2009), pp. 91-119

[4] Bear, J.B., Woolley, A.W.: The role of gender in team collaboration and performance. Interdisciplinary Science Reviews 36, (2011), pp. 146-153

[5] Beck, K., et al.: Manifesto for Agile Software Development. (2001) http://www.agilemanifesto.org/

[6] Behutiye, W.N., et al.: Analyzing the concept of technical debt in the context of agile software development: A systematic literature review. Information and Software Technology 82, (2017), pp. 139-158

[7] Boehm, B.W.: A Spiral Model of Software Development and Enhancement. IEEE Computer 21, (1988), pp. 61-72

[8] Cao, L., et al.: A framework for adapting agile development methodologies. European Journal of Information Systems 18, (2009), pp. 332-343

[9] Charmaz, K.: Constructing grounded theory: A practical guide through qualitative analysis. Sage (2006)

[10] Chua, C.E.H., Myers, M.D.: Social control in information systems development: a negotiated order perspective. Journal of Information Technology 33, (2018), pp. $173-187$
[11] Cockburn, A., Highsmith, J.: Agile Software Development: The People Factor. IEEE Computer 34, (2001), pp. 131-133

[12] Conboy, K.: Agility from First Principles: Reconstructing the Concept of Agility in Information Systems Development. Information Systems Research 20, (2009), pp. 329-355

[13] Conboy, K., Carroll, N.: Implementing Large-Scale Agile Frameworks: Challenges and Recommendations. IEEE Software 36, (2019), pp. 44-50

[14] Cramer, M., Zaveri, M.: What if You Don't Want to Go Back to the Office? New York Times, (2020)

[15] CRAMTOM, C.D., Hinds, P.J.: INTERCULTURAL INTERACTION IN DISTRIBUTED TEAMS: SALIENCE OF AND ADAPTATIONS TO CULTURAL DIFFERENCES. In: Academy of Management Proceedings, pp. 1-6.Academy of Management Briarcliff Manor, NY 10510 (2007)

[16] Craven, M., et al.: COVID-19 and the great reset: Briefing note, July 9, 2020. McKinsey \& Company (2020)

[17] Cunningham, W.: The WyCash portfolio management system. ACM SIGPLAN OOPS Messenger 4, (1992), pp. 29-30

[18] Diegmann, P., et al.: Journey Towards Agility: Three Decades of Research on Agile Information Systems Development. Thirty Ninth International Conference on Information Systems, San Francisco, USA (2018)

[19] Dingsoeyr, T., et al.: Agile Development at Scale: The Next Frontier. IEEE Software 36, (2019), pp. 30-38

[20] Dorairaj, S., et al.: Understanding team dynamics in distributed Agile software development. In: International conference on agile software development, pp. 4761.Springer (2012)

[21] Dreesen, T., et al.: Beyond the Border: A Comparative Literature Review on Communication Practices for Agile Global Outsourced Software Development Projects. In: 2016 49th Hawaii International Conference on System Sciences (HICSS), pp. 4932-4941, (2016)

[22] Dreesen, T., et al.: The Impact of Modes, Styles, and Congruence of Control on Agile Teams: Insights from a Multiple Case Study. In: 53rd Hawaii International Conference on System Sciences (HICSS), (2020)

[23] Dybå, T., Dingsøyr, T.: Empirical studies of agile software development: A systematic review. Information and software technology 50, (2008), pp. 833-859

[24] Edmondson, A.: Psychological safety and learning behavior in work teams. Administrative science quarterly 44, (1999), pp. 350-383

[25] Eisenhardt, K.M.: Building theories from case study research. Academy of management review 14, (1989), pp. $532-550$

[26] Ellis, C.A., et al.: Groupware: some issues and experiences. Commun. ACM 34, (1991), pp. 39-58

[27] Espinosa, J.A., et al.: Familiarity, complexity, and team performance in geographically distributed software development. Organization science 18, (2007), pp. 613-630 [28] Fruhling, A., de Vreede, G.-J.: Field Experiences with eXtreme Programming: Developing an Emergency Response System. Journal of Management Information Systems 22, (2006), pp. 39-69 
[29] Gregory, R.W., et al.: IT Consumerization and the Transformation of IT Governance. MIS Quarterly 42, (2018), pp. 1225-1253

[30] Hennel, P., Rosenkranz, C.: Putting the "Socio" into the Development of Socio- Technical Systems - The Case for Psychological Safety in Agile Information Systems Development. Project Management Journal, (forthcoming) [31] Hoda, R., et al.: Developing a grounded theory to explain the practices of self-organizing Agile teams. Empirical Software Engineering 17, (2012), pp. 609-639

[32] Huang Chua, C.E., Myers, M.D.: Social control in information systems development: A negotiated order perspective. Journal of Information Technology 33, (2018), pp. 173-187

[33] Huang, J., et al.: Growing on steroids: Rapidly scaling the user base of digital ventures through digital innovaton. Mis Quarterly 41, (2017),

[34] Hummel, M., et al.: The Role of Communication in Agile Systems Development. BUSINESS AND INFORMATION SYSTEMS ENGINEERING 5, (2013), pp. 343-355

[35] Hummel, M., et al.: The role of social agile practices for direct and indirect communication in information systems development teams. Communications of the Association for Information Systems 36, (2015), pp. 15

[36] Iivari, J., Iivari, N.: The relationship between organizational culture and the deployment of agile methods. Information and Software Technology 53, (2011), pp. 509-520

[37] Kalenda, M., et al.: Scaling agile in large organizations: Practices, challenges, and success factors. Journal of Software: Evolution and Process 30, (2018), pp. e1954

[38] Kirsch, L.J., et al.: Investigating the antecedents of team-based clan control: Adding social capital as a predictor. Organization Science 21, (2010), pp. 469-489

[39] Kozlowski, S.W., Ilgen, D.R.: Enhancing the Effectiveness of Work Groups and Teams. Psychological Ccience in the Public Interest 7, (2006), pp. 77-124

[40] Lee, G., Xia, W.: Toward Agile: An Integrated Analysis of Quantitative and Qualitative Field Data on Software Development Agility. MIS Quarterly 34, (2010), pp. $87-115$

[41] Leffingwell, D.: Scaled Agile Framework® (SAFe) 5.0. (2020) https://www.scaledagileframework.com/

[42] Lindsjørn, Y., et al.: Teamwork quality and project success in software development: A survey of agile development teams. Journal of Systems and Software 122, (2016), pp. 274-286

[43] Maruping, L.M., et al.: Role of collective ownership and coding standards in coordinating expertise in software project teams. European Journal of Information Systems 18, (2009), pp. 355-371

[44] Miles, M.B., Huberman, A.M.: Qualitative data analysis : an expanded sourcebook. Sage Publications, Thousand Oaks (1994)

[45] Muir, D.E., Weinstein, E.A.: The social debt: An investigation of lower-class and middle-class norms of social obligation. American Sociological Review 27, (1962), pp. 532-539
[46] Nahapiet, J., Ghoshal, S.: Social capital, intellectual capital, and the organizational advantage. Academy of management review 23, (1998), pp. 242-266

[47] Peng, X., et al.: Collaborative Software Development Platforms for Crowdsourcing. IEEE Software 31, (2014), pp. 30-37

[48] Ralph, P., et al.: Pandemic Programming: How COVID-19 affects software developers and how their organizations can help. Empirical Software Engineering under review, (2020),

[49] Ramesh, B., et al.: Can Distributed Software Development be Agile?: Three organizations studied here suggest the answer is "yes," when the unique characteristics of both environments are successfully blended. Communications of the ACM October 2006, (2006), pp. 41-46

[50] Reagans, R., Zuckerman, E.W.: Networks, diversity, and productivity: The social capital of corporate $R \& D$ teams. Organization science 12, (2001), pp. 502-517

[51] Recker, J., et al.: How agile practices impact customer responsiveness and development success: A field study. Project Management Journal 48, (2017), pp. 99-121

[52] Royce, W.W.: Managing the Development of Large Software Systems: Concepts and Techniques. In: Proceedings of WesCon, (1970)

[53] Saldaña, J.: The coding manual for qualitative researchers. SAGE, London (2016)

[54] Sandberg, J., et al.: Digitization and Phase Transitions in Platform Organizing Logics: Evidence from the Process Automation Industry. MIS Quarterly 44, (2020), pp. 129153

[55] Sarker, S., Sarker, S.: Exploring Agility in Distributed Information Systems Development Teams: An Interpretive Study in an Offshoring Context. Information Systems Research 20, (2009), pp. 440-462

[56] Spurk, D., Straub, C.: Flexible employment relationships and careers in times of the COVID-19 pandemic. Elsevier (2020)

[57] Strauss, A., Corbin, J.: Basics of qualitative research. Sage, London (1998)

[58] Tamburri, D.A., et al.: What is social debt in software engineering? In: 2013 6th International Workshop on Cooperative and Human Aspects of Software Engineering (CHASE), pp. 93-96.IEEE (2013)

[59] Tamburri, D.A., et al.: Social debt in software engineering: insights from industry. Journal of Internet Services and Applications 6, (2015), pp. 10

[60] Tamburri, D.A.: Software architecture social debt: managing the incommunicability factor. IEEE Transactions on Computational Social Systems 6, (2019), pp. 20-37

[61] Tamburri, D.A.A., et al.: Exploring community smells in open-source: An automated approach. IEEE Transactions on Software Engineering 14, (2017),

[62] Tripp, J.F., et al.: Job satisfaction in agile development teams: Agile development as work redesign. Journal of the Association for Information Systems 17, (2016), pp. 1

[63] VersionOne: The 14th Annual State Of Agile Report. (2020)

[64] Yin, R.K.: Case Study Research: Design and Methods. SAGE Publications Inc., Thousand Oaks, CA, USA (2003) 